\title{
Identification of Factors Most Important for Ammonia Emis- sion from Fertilized Soils for Potato Production Using Principal Component Analysis
}

\author{
Guodong Liu', Yuncong Li², Kati W. Migliaccio ${ }^{3}$, Ying Ouyang ${ }^{4}$, and Ashok K. Alva ${ }^{5}$
}

1 Horticultural Sciences Department, University of Florida, Gainesville, 1117 Fifield Hall, PO Box 110690 , Florida 3261 1-0690, USA; ${ }^{2}$ Department of Soil and Water Sciences, Tropical Research and Education Center, University of Florida, 18905 SW 280th St., Homestead, FL 33031, USA; ${ }^{3}$ Agricultural \& Biological Engineering, Tropical Research \& Education Center, University of Florida, $18905 \mathrm{SW} 280^{\text {th }}$ St., Homestead, FL 33031, USA; ${ }^{4}$ USDA Forest Service, 100 Stone Blvd, Thomson Hall, Room 309, Mississippi S, MS 39762, USA; ${ }^{5}$ Vegetable and Forage Crops Research Laboratory, USDA-ARS, 24106 N. Bunn Rd., Prosser, WA 99350, USA

Received: August 10, 2010 / Accepted: February 5, 2011

\begin{abstract}
Ammonia $\left(\mathrm{NH}_{3}\right)$ emissions from fertilized soils are a costly problem that is undermining agricultural and ecological sustainability worldwide. Ammonia emissions from crop production have been reliably documented in recent years. However, insufficient efforts have been made to determine the factors most influential in facilitating $\mathrm{NH}_{3}$ emissions. The goal of this study was to identify the principal factors facilitating $\mathrm{NH}_{3}$ emissions from fertilized soils for potato production by means of principal component analysis (PCA). A dataset consisting of $\mathbf{1 4}$ different variables and $\mathbf{6 0 0}$ determinations of $\mathrm{NH}_{3}$ emission rates was geometrically classified into 5 zones, and then analyzed with the PCA technique. The data used in this analysis originated from an incubation experiment involving four major potato production soils (two from Washington State and two from Florida, USA), five N sources, two soil water regimes, three incubation temperatures and five measurement dates of $\mathrm{NH}_{3}$ emission rates during 28 days of incubation: Day 1, 3, 7, 14, and 28. Ammonia emission rates was classified into five distinct zones. In
\end{abstract}

* Corresponding authors: guodong@ufl.edu \& yunli@ufl.edu the five zones the total variance in $\mathrm{NH}_{3}$ emission was accounted for as follows: soil particle size distribution, electrical conductivity (EC), field capacity, and bulk density, $47 \%$; fer tilizer sources, $15 \%$; soil $\mathrm{pH}, 12 \%$; and soil temperature and the soil water regime $9 \%$. The effects of the principal components on $\mathrm{NH}_{3}$ emission in descending order were as follows: soil type $>$ fertilizer source $>$ soil $\mathrm{pH}>$ soil temperature and water regime. Therefore, $\mathrm{NH}_{3}$ emissions could be reduced potentially with amendment of coarse textured agricultural soils to reduce their bulk density, selection of fertilizers to lessen those with the ammonium compounds, use of amendments to lower soil $\mathrm{pH}$, and optimal water management.

Keywords: Ammonia volatilization - Fertilized soils - Principal component analysis (PCA) • Soil type.

Abbreviations: $E C$, electrical conductivity; $F C$, field capacity; nBTPT, N-(n-butyl) thiophosphoric triamide; PC, principal component; PCA, Principal component analysis. 


\section{Introduction}

Ammonia $\left(\mathrm{NH}_{3}\right)$ is the third most abundant nitrogen $(\mathrm{N})$ gas after $\mathrm{N}_{2}$ and $\mathrm{N}_{2} \mathrm{O}$ in the atmosphere. Crop and livestock production contributes approximately $90 \%$ of total $\mathrm{NH}_{3}$ emitted into the atmosphere (Schlesinger and Hartley, 1992; Ferm, 1998). In Western Europe, about $92 \%$ of all emitted $\mathrm{NH}_{3}$ was traced to agricultural origins (Kirchmann et al., 1998). Fertilization of crops alone contributes more than 50 percent of the global emission of $\mathrm{NH}_{3}$ (FAO, 2001). Nitrogen loss to the environment has been a major concern for many decades (Ma et al., 2008). Reductions in $\mathrm{NH}_{3}$ emission from agricultural production practices are imperative to enhance $\mathrm{N}$ utilization efficiency and improve air quality (Breeman et al., 1982; Buijsman et al., 1987; Fangmeier et al., 1994; Kirchmann et al., 1998; Gay and Knowlton, 2005; Aneja et al., 2006). Indeed since the mid-1800s, some attention has been given to the development of effective strategies to minimize $\mathrm{NH}_{3}$ emission (Sprengel, 1839; Boussingault, 1851 ; Bussink and Oenema, 1998). Major factors which influence the extent of $\mathrm{NH}_{3}$ emission have been shown to include the N application rate (Vlek and Stumpe, 1978), N source (Fenn and Kissel, 1973), soil pH (Bremner and Douglas, 1971; He et al., 1999; Liu et al., 2007), temperature (Liu et al., 2007), soil water regime (Fox and Hoffman, 1981; Liv et al., 2007), and soil organic matter content (Paulson and Kurtz, 1969). To reduce $\mathrm{NH}_{3}$ emission from livestock production operations, shallow manure slurry injection and urease inhibitors have been employed (Hansen et al., 2003; Singh et al., 2009). Urease inhibitors such as $\mathrm{N}$-(n-butyl) thiophosphoric triamide (nBTPT) are recommended to control nitrogen loss from urea via $\mathrm{NH}_{3}$ emission (Watson et al., 1994 and Watson et al., 2008; Sanz-Cobena et al., 2008). The reduction of $\mathrm{NH}_{3}$ emission from fertilized soils is achievable by application to paddy rice at panicle initiation compared to broadcasting at transplanting is 50 percent (FAO, 2001). Fenn et al. (1981) found that soluble calcium and magnesium reduced $\mathrm{N}$ loss via $\mathrm{NH}_{3}$ emission. Fenn and Hossner (1985) comprehensively summarized the effects of fertilizer type, application method, soil properties, and temperature and soil water on $\mathrm{NH}_{3}$ emission. However, the magnitude of influence by each of the above factors within a given system is not clearly understood. Also, the effects of soil type including particle size distribution, bulk density, electrical conductivity, and field capacity on $\mathrm{NH}_{3}$ emission have not been fully investigated.

The identification of key variables that might be managed to reduce $\mathrm{NH}_{3}$ emissions and improve air quality as well as $\mathrm{N}$ uptake efficiency by crops is far from simple and presents a complex problem in statistical analysis. Principal component analysis (PCA), originated by Pearson (1901) and further developed by Hotelling (1933), was applied extensively in research on analysis of data involved in telephonic communications and engineering in 1960s (Rao, 1964; Gnanadesikan, 1977). Since 1970s, PCA has been used in chemistry to gain insight into spectral data of systems containing a mixture of chemical compounds that contribute to a spectral signature (Beauchemin et al., 2002). The power of this multivariate statistical tool to interpret large datasets was demonstrated by Malinowski (1991) and Beauchemin et al. (2002) in the identification of principal factors in datasets involving absorption and emission spectra, gas chromatography, mass spectrometry, and nuclear magnetic resonance spectroscopy.

During the 1990s, the PCA approach was successfully applied to characterize the distribution of vegetation (Hirosawa et al., 1996), protein dynamics (Balsera et al., 1996) and molecular biology such as DNA microarrays (Raychaudhuri et al., 2000). Recently, the PCA approach was effectively employed in water quality analysis (Ouyang, 2005). The above studies have demonstrated the application of PCA to reduce dimensionality and to delineate the most important factors responsible for the most variation and thus extract the essential factors from large and multivariate data sources. Therefore, it seemed important to apply the PCA analysis to sort out the major factors contributing to $\mathrm{NH}_{3}$ emissions from soil-applied $\mathrm{N}$ fertilizers in irrigated potato production systems and that is the main thrust of this study. The objectives of this study were: (i) to identify the principal factors affecting $\mathrm{NH}_{3}$ emissions from fertilized soils used for potato production, and (ii) to assess the differential impact of these factors on $\mathrm{NH}_{3}$ emission.

\section{Materials and Methods}

$\mathrm{NH}_{3}$ emission rates in this study vary widely and range from 0.1 to $6183.4 \mathrm{~g} \mathrm{~N} \mathrm{ha}^{-1} \mathrm{~d}^{-1}$. There is almost nothing for the control without $\mathrm{N}$ fertilization and the treatment of $\mathrm{KNO}_{3}$. However, more than $70 \%$ of $\mathrm{NH}_{3}$ emissions from the other three treatments amended with either $\mathrm{NH}_{4} \mathrm{NO}_{3},\left(\mathrm{NH}_{4}\right)_{2} \mathrm{SO}_{4}$, or urea are completed in the first week after $\mathrm{N}$ fertilization (Liv et al., 2007). The statistical results of a dataset with such large variability may be seriously distorted due to the huge heterogeneity in the measured observations. To avoid such a distortion, the dataset needs to be divided into groups for being analyzed by the PCA technique. Classification, which involves the detection in the relationships between the variables, is employed for this purpose. In this study, geometric classification is used for dividing a dataset into different groups. In geometry, the data can be considered as having a homogenous property when the classified data share an analogous slope (Shani et al., 2005). The method for classification based on slopes of curves is defined as the geometric classification of data. Geometric classification is a process of dividing a dataset into mutually exclusive groups in which the data are close together within a group but quite distant between and among the different groups. The numerical separation between different groups is measured with respect to a specific variable such as the $\mathrm{NH}_{3}$ emission rate, which we employed in this study.

\subsection{Data Source}

The dataset used in this study included 600 measurements of $\mathrm{NH}_{3}$ emission rates ( $\mathrm{g} \mathrm{N} \mathrm{ha}{ }^{-1} \mathrm{day}^{-1}$ ) in a laboratory study with the following four soils: Biscayne Marl Soil (loamy, carbonatic, Hyperthermic, shallow Typic Fluvaquents), Krome Gravelly Loam (loamy-skeletal carbonic, hyperthermic Lithic Udorthents), Quincy Fine Sand (Mixed, Mesic Xeric Torripsamments), and Warden Silt Loam (Coarse-silty, mixed, Mesic, Xerollic Camborthids). The 
major potato production regions in Florida are represented by the first two mentioned soils, while those in the State of Washington are represented by the third and fourth mentioned soils. Four $\mathrm{N}$ sources commonly used in potato production in these states were $\mathrm{KNO}_{3}, \mathrm{NH}_{4} \mathrm{NO}_{3},\left(\mathrm{NH}_{4}\right)_{2} \mathrm{SO}_{4}$ and $\left(\mathrm{NH}_{2}\right)_{2} \mathrm{CO}$ and a control treatment (without $\mathrm{N}$ application) was also evaluated.

The investigation of ammonia emission involved the following variables: (i) three incubation temperatures, i.e., 11, 20, and $29^{\circ} \mathrm{C}$, which are the minimum, mean, and maximum temperatures of the Washington potato production season, respectively, and the corresponding temperatures of the Florida potato production season are similar; (ii) two soil water regimes: $20 \%$ and $80 \%$ of field capacity (FC), which are the two soil moisture extremes before and after each irrigation event, respectively; and (iii) sampling at 5 times after fertilizer application, i.e., $1,3,7,14$, and 28 days. Thus, a total of 600 combinations $(4 \times 5 \times 3 \times 2 \times 5)$ of factors were performed each in triplicate. Every datum was the average of the three replications in this study. Characteristics of the soils involved and detailed descriptions of the methods used can be found in Liu et al. (2007).

In brief, $\mathrm{NH}_{3}$ volatilization was measured by trapping $\mathrm{NH}_{3}$ with sponges spiked in a trapping solution, containing concentrated phosphoric acid, glycerol, and deionized water. The concentration of $\mathrm{NH}_{4}^{+}-\mathrm{N}$ was analyzed using an Autoanalyzer 3 (Bran+Luebbf GmbH, Werkstrasse, Norderstedt, Germany, www.bran-luebbe.de) according to US-EPA Method 350.1 (EPA, 1993).

\subsection{Geometric Classification}

The $\mathrm{NH}_{3}$ emission rates with 600 data points from the fertilized soils were sorted from maximum to minimum and numbered from 1 to 600 using Microsoft Excel 2007. The emission rates were plotted on the $y$-axis and the data numbers were plotted on the x-axis. Then the data points were regressed to the following exponential function.

$$
\begin{aligned}
& y=2032.6 e^{-0.0149 x} \\
& R^{2}=0.99 \\
& p<0.0001
\end{aligned}
$$

Based on the derivative principle in mathematics, any nonlinear curve can be approximated as a number of linear curves with different slopes; in addition a nonlinear curve can be fitted in a piecewise manner (Shani et al., 2005). The data in this study were classified based on the trend line of the $\mathrm{NH}_{3}$ emission rate vs. the datum number by means of a 2 -step procedure, as follows. In step 1: the dataset was divided into three zones because the trend line has three distinct zones, i.e., a steep linear zone, a curvilinear transition zone, and a flat linear zone (Fig. 1). Thus, there are two linear zones and one non-linear zone (curvilinear transition zone). In step 2: the curvilinear transition zone was further grouped into three quasi-linear zones with different slopes. Therefore, the entire range of $\mathrm{NH}_{3}$ emission rates vs. data numbers was divided into five separate linear or quasi-linear zones with slope ranges of: $\leq-200$ for data points 1 through $20, \leq-20$ for data points 21 through 66, $\leq-2$ for data points 67 through
220 , $\leq-0.2$ for data points 221 through 374 , and $\leq-0.02$ for data points 375 through 600 . The assumption used in this classification was that all of the data points in each separate zone have a very similar slope but that the different consecutive zones have distinct slopes differing by 10 -fold. The assumption for this classification can also be different. For example, the distinct slopes may differ by 5 - or 20 -fold between every two different consecutive zones. However, the former scenario (5-fold) has too many zones that are too complicated to be understood. The latter scenario (20-fold) has too few zones that over-simplify the information the dataset has and this scenario can't be fully understood. Thus, the distinct slopes between every two consecutive zones with 10-fold numerical separation are considered suitable in this study.

\subsection{Analysis Procedures}

Fourteen variables were included in this analysis (Table 1). The PRINCOMP package from the Statistical Analysis System (SAS) software (version 9.1.3, SAS Institute, 2009) was used to perform the PCA analysis in this study. The PCA analysis was conducted on the standardized variables using a covariance matrix (Ouyang, 2005; Ouyang et al., 2006). In previous studies involving this statistical tool, a cumulative variance was considered as statistically significant with that variance was greater than $75 \%$ (Ouyang, 2005), 80\% (Zhao, 2003) or 85\% (Hao et al., 2003). In this study, a cumulative variance that is greater than $80 \%$ was considered as significant statistically. This slightly conservative criterion was selected because the soils used were heterogeneous and the treatments were diverse.

\section{Results and Discussion}

\subsection{Geometric Classification of Observation Dataset}

Based on a classification by geometric means, the nonlinear curve of the $\mathrm{NH}_{3}$ emission rates across all samples was represented as the five linear lines described above. Thus the entire $\mathrm{NH}_{3}$ emission rate curve was segmented into 5 separate range zones based on major differences in the slopes of the $5 \mathrm{seg}$ ments as shown in Table 2 and Fig. 1.

Based on the range of $\mathrm{NH}_{3}$ emission rates in each of the 5 zones (see Table 2), there were five corresponding minimum and maximum values of $\mathrm{NH}_{3}$ emission rates. By taking each maximum value as the $y$-coordinate for each zone's linear function, then the quotient of delta $y$ to delta $x$ in each zone was the slope of the line segment. Thus the line segment in each the five zones (Fig. 2) could be described as follows:

$$
\begin{aligned}
& y_{A}=-208.5100 x+5252.8 \\
& R^{2}=0.84 \\
& p<0.0001
\end{aligned}
$$




$$
\begin{aligned}
& y_{B 1}=-20.8560 x+2018.2 \\
& R^{2}=0.97 \\
& p<0.0001 \\
& y_{B 2}=-3.5523 x+795.4 \\
& R^{2}=0.93 \\
& p<0.0001 \\
& y_{B 3}=-0.4789 x+171.7 \\
& R^{2}=0.90 \\
& p<0.0001 \\
& y_{C}=-0.0211 x+12.3 \\
& R^{2}=0.95 \\
& p<0.0001
\end{aligned}
$$

Table 1. Variables in the investigation of principal factors governing ammonia emissions from fertilized soils used for potato production in Florida and Washington State.

Fertilizers applied $\left(\mathrm{kg} \mathrm{N} \mathrm{ha}^{-1}\right)$

$$
\mathrm{NH}_{4} \text {-form: } 0-75.0
$$

Soil particle size distribution $\left(\mathrm{g} \mathrm{kg}^{-1}\right)$ :

Clay: 19-175

Silt: $112-732$

Sand: 93-869

Soil basic characteristics:

\begin{tabular}{|c|c|c|c|c|c|c|c|}
\hline \multirow[b]{2}{*}{ Zone } & \multirow{2}{*}{$\begin{array}{l}\text { Number } \\
\text { of data }\end{array}$} & \multirow{2}{*}{$\begin{array}{l}\text { Data No. } \\
\text { range }\end{array}$} & \multirow[b]{2}{*}{ Slope } & \multirow{2}{*}{$\begin{array}{l}\mathrm{NH}_{3} \text { emission } \\
\text { Rate range }\end{array}$} & \multirow{2}{*}{$\begin{array}{c}\text { Average } \\
\text { rate }\end{array}$} & \multicolumn{2}{|c|}{ Data No. } \\
\hline & & & & & & $20 \% \mathrm{FC}$ & $80 \% \mathrm{FC}$ \\
\hline & & & & $\ldots-\cdot \cdot g N h a^{-1} \cdot d$ & $y^{-1} \ldots . . .$. & $\ldots$ & ......... \\
\hline A & 20 & $1-20$ & -208.5100 & $1700.9-6183.4$ & 3064.4 & 90.0 & 10.0 \\
\hline$B 1$ & 46 & $21-66$ & -20.8560 & $728.1-1700.8$ & 1111.0 & 71.7 & 28.3 \\
\hline B2 & 154 & $67-220$ & -3.5523 & $81.7-728.0$ & 285.7 & 51.7 & 48.7 \\
\hline B3 & 154 & $221-374$ & -0.4789 & $5.4-81.6$ & 29.2 & 44.2 & 55.8 \\
\hline C & 226 & $375-600$ & -0.0211 & $0.1-5.3$ & 2.1 & 45.1 & 54.9 \\
\hline
\end{tabular}

Bulk density $\left(\mathrm{g} \mathrm{cm}^{-3}\right): 0.88-1.43$

Electrical conductivity (EC, $\mu \mathrm{S} / \mathrm{cm}): 49-457$

Field capacity (FC, g/ $100 \mathrm{~g}$ soil): $24.74-60.45$

Organic matter (, \%): 0.41-1.79

$\mathrm{pH}: 6.46-7.69$

Sampling time (d): $1,3,7,14$, and 28

Soil water regime (\% FC): 20 and 80

Temperature $\left({ }^{\circ} \mathrm{C}\right): 11,20$, and 29

Rate of ammonia volatilization $\left(\mathrm{g} \mathrm{N} \mathrm{ha}^{-1} \mathrm{day}^{-1}\right): 0.1-6183.4$

Table 2. Classification of 600 determinations of rates of $\mathrm{NH}_{3}$ emission in an incubation experiment involving four types of soils, four $\mathrm{N}$ sources plus a control without fertilization, three incubation temperatures, and two soil water regimes.

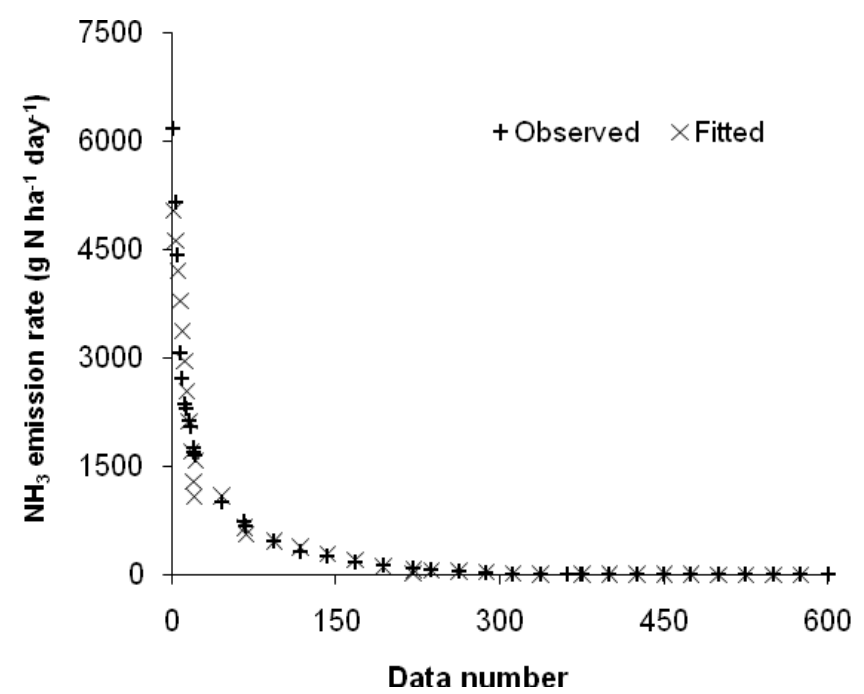

Fig. 1. The observed curve of $600 \mathrm{NH}_{3}$-emission rates on fertilized soils from Florida and Washington State and its five linearly fitted zones: $A$, $B 1, B 2, B 3$, and C. To make the figure clearer the data were thinned. The data-thinning was done by retaining the first and last points in each linear line and retaining data at increment of 2 for zone $A$, and increment of 25 for the zones B1, B2, B3, and C. Thus, 600 data points were reduced to 39 .

Accordingly, we developed a fitted matrix from Eqs. 2 through 6. Subsequently, a graph was plotted based on the observed and fitted data, which required only 39 data points as described below. The data-thinning was accomplished by retaining the first and last data points in each zone. In addition every second data point was retained in Zone $A$, and every 25 th data point was retained in the remaining zones; i.e. B1, B2, B3, and C. Thus the 600 data points were reduced to just the 39 as shown in Fig. 1.

The mean $\mathrm{NH}_{3}$ emission rate in zone $\mathrm{A}$ was the highest at $3,064.4 \mathrm{~g} \mathrm{~N} \mathrm{ha}^{-1}$ day $^{-1}$ and the earliest to occur with a mean of 2.0 days of incubation. In contrast, the mean $\mathrm{NH}_{3}$ emission rate in zone $\mathrm{C}$ was the lowest at $2.1 \mathrm{~g} \mathrm{~N} \mathrm{ha}^{-1}$ day $^{-1}$ and the last to occur with a mean of 13.8 days of incubation. Both mean $\mathrm{NH}_{3}$ emission rates and mean days of incubation were intermediate in Zones B1, B2, and B3 (see Table 2). Based on the distributions of $\mathrm{NH}_{3}$ emission rates and days of incubation, $\mathrm{NH}_{3}$ emissions in Zones $\mathrm{A}, \mathrm{B} 1, \mathrm{~B} 2, \mathrm{~B} 3$, and $\mathrm{C}$ were designated as maximum, fast, medium, slow, and minimum, respectively.

Since high $\mathrm{NH}_{4}^{+}$concentrations are one of the major drivers of rapid $\mathrm{NH}_{3}$ emissions from the soils, split applications of $\mathrm{N}$ fertilizers should be highly recommended in order to minimize $\mathrm{NH}_{3}$ emissions to improve $\mathrm{N}$ uptake efficiency and to protect air quality (Sowers et al., 1994). Additionally, Table 2 indicates that $90.0,71.7,51.7,44.2$ and $45.1 \%$ of the data of Zones $A, B 1$, $B 2, B 3$, and C, respectively, were from dry $(20 \% \mathrm{FC})$ soil. In the medium zone, Zone B2, approximately half of the data points were contributed from either the $20 \%$ FC soil water regime or the $80 \% \mathrm{FC}$ soil water regime. However, for the maximum Zone $A$ and the fast Zone B1, 90 and $71.7 \%$, respectively, of the data points were contributed by the $20 \%$ FC soil water regime. This 
Table 3. Variables in the investigation of principal factors governing ammonia emissions from fertilized soils used for potato production in Florida and Washington State.

\begin{tabular}{|c|c|c|c|c|c|}
\hline \multirow[b]{2}{*}{ Factor } & \multicolumn{5}{|c|}{ Correlation Coefficients } \\
\hline & Zone A & Zone B1 & Zone B2 & Zone B3 & Zone C \\
\hline Bulk density & 0.0443 & 0.0564 & -0.1227 & 0.1178 & -0.0201 \\
\hline Clay content & 0.0367 & -0.0494 & $0.1612 *$ & -0.1157 & 0.0374 \\
\hline Electrical Conductivity & -0.0525 & -0.0562 & 0.1352 & $-0.1366^{\dagger}$ & 0.0337 \\
\hline Field capacity & -0.0741 & -0.0581 & 0.1214 & $-0.1353^{\dagger}$ & 0.0270 \\
\hline Incubation Time & $-0.4088^{\dagger}$ & $-0.3353^{*}$ & $-0.1515^{\dagger}$ & -0.0267 & $-0.5105^{* * *}$ \\
\hline $\mathrm{NH}_{4}^{+}-\mathrm{N}$ rate & 0.2709 & 0.0210 & 0.1074 & $0.3873^{* * *}$ & -0.0575 \\
\hline $\mathrm{NO}_{3}-\mathrm{N}$ rate & -0.2709 & -0.0210 & -0.1074 & $-0.2052 *$ & $0.2223 * *$ \\
\hline Organic matter & $0.3810^{\dagger}$ & -0.0100 & $0.1430^{\dagger}$ & -0.0124 & 0.0169 \\
\hline $\mathrm{pH}$ & $0.4143^{\dagger}$ & 0.0047 & $0.1523^{\dagger}$ & 0.0023 & 0.0292 \\
\hline Sand content & 0.0536 & 0.0569 & -0.1148 & 0.1143 & -0.0159 \\
\hline Silt content & -0.0790 & -0.0581 & 0.0991 & -0.1105 & 0.0092 \\
\hline Soil water regime & -0.2634 & 0.0292 & -0.0757 & -0.0166 & 0.0769 \\
\hline Temperature & -0.0240 & 0.0589 & 0.0971 & -0.1307 & 0.0495 \\
\hline$r_{0.10, \mathrm{df}} \pi$ & 0.3783 & 0.2455 & 0.1333 & 0.1333 & 0.1101 \\
\hline$r_{0.05, d f}$ & 0.4438 & 0.2905 & 0.1586 & 0.1586 & 0.1312 \\
\hline 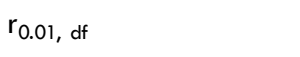 & 0.5614 & 0.3758 & 0.2076 & 0.2076 & 0.1722 \\
\hline$r_{0.001, d f}$ & 0.6788 & 0.4687 & 0.2901 & 0.2901 & 0.2423 \\
\hline
\end{tabular}

\section{$\begin{array}{lllllll}\square C & \square P C 2 & \square P C 3 & \square P C 4 & \square P C 5 & \square P C 6 & \square P C 7\end{array}$}

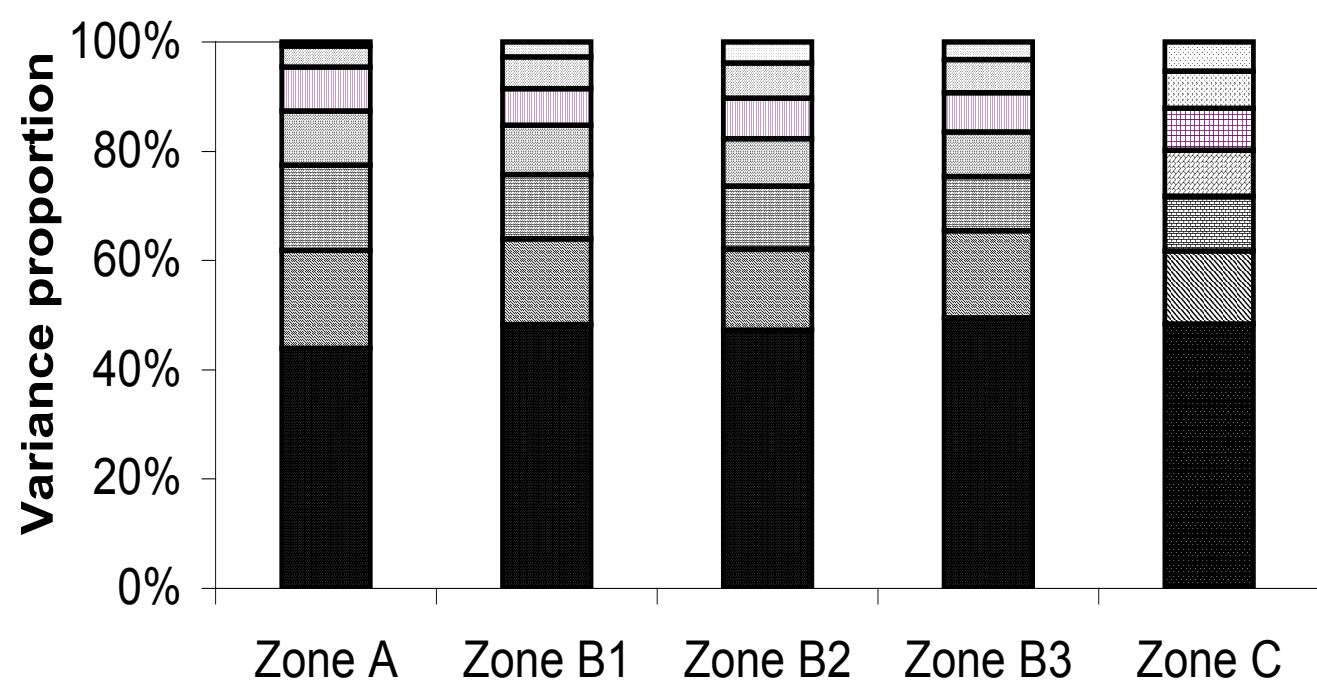

Fig. 2. Soil type, the first principal component $(\mathrm{PC1})$ in each of the five zones contributed approximately to $50 \%$ of the variance in $\mathrm{NH}_{3}$ emission. The first four PCs basically explained up to $87.1 \%$ of variance. The first four PCs are as follows: $\mathrm{PCl}$, soil type; $\mathrm{PC} 2, \mathrm{NH}_{4}{ }^{+}$and $\mathrm{NO}_{3}{ }^{-} ; \mathrm{PC} 3$, soil $\mathrm{pH}$; and $\mathrm{PC} 4$, temperature and soil moisture. 
observation suggests that dry soil was a major factor associated high $\mathrm{NH}_{3}$ emission rates. Given the low soil water regime the transport of $\mathrm{NH}_{4}^{+}$ions from the surface soil into deeper soil was strongly restricted. Therefore, $\mathrm{NH}_{4}^{+}$ions formed in the surface soil were more vulnerable to conversion to $\mathrm{NH}_{3}$, which in turn was readily subject to volatilization. These results show that the establishment and maintenance of an appropriate soil - water regime is essential for controlling $\mathrm{N}$ loss via $\mathrm{NH}_{3}$ emission from the fertilized soils tested in this study.

\subsection{Correlations Between $\mathrm{NH}_{3}$ Emission Rate and Other Factors}

Correlation analysis was done for each of the five zones (Table 3). Ammonia emission rates in Zone A were rapid (see Table 2). The major factors that impacted the $\mathrm{NH}_{3}$ emission rate were $\mathrm{pH}$ followed by duration of incubation. The time range for Zone A was only 3 days with frequencies of $\mathrm{NH}_{3}$ determinations of $60.0 \%$ and $40.0 \%$ for days 1 and 3, respectively. Organic matter also influenced $\mathrm{NH}_{3}$ emission rates significantly at $\mathrm{p}<0.10$ (see Table 3).

The $\mathrm{NH}_{3}$ emission rates in the fast emission zone (B1) ranged from 728.1 to $1700.8 \mathrm{~g} \mathrm{Nha}^{-1} \mathrm{~d}^{-1}$ with an average of 1111.0 $\mathrm{g} \mathrm{N} \mathrm{ha}^{-1} \mathrm{~d}^{-1}$ (see Table 2). Within this zone only incubation time had a statistically significant impact on the $\mathrm{NH}_{3}$ emission rates $(R=-0.3353)$ at $p<0.05$ (see Table 3$)$. In the medium emission zone (B2), clay content showed significant impact on $\mathrm{NH}_{3}$ emission rates at $p<0.05$; while the impacts of incubation time, organic matter and $\mathrm{pH}$ were significant at $\mathrm{p}<0.10$. In Zone B3, the slow emission zone, the time distribution primarily spanned the first two weeks. The $50^{\text {th }}$ and $75^{\text {th }}$ percentile of time distribution in this zone occurred in the first 7 and 14 days, respectively. The $\mathrm{NH}_{3}$ emission rates in this zone were low but were strongly influenced by $N$ source $(p<0.001$ ), and weakly influenced by electrical conductivity $(p<0.10)$ and by $\%$ of field capacity ( $p$ $<0.10$ ) (see Table 3).

The very low $\mathrm{NH}_{3}$ emission rates in Zone $\mathrm{C}$ ranged from 0.1 to $5.3 \mathrm{~g} \mathrm{~N} \mathrm{ha}^{-1}$ day $^{-1}$ with an average of $2.1 \mathrm{~g} \mathrm{~N} \mathrm{ha}^{-1} \mathrm{~d}^{-1}$ and a mode time of day 28, which occurred almost in one third of the time period. In this zone, $\mathrm{NH}_{3}$ emission rates decreased significantly with time. $\mathrm{NO}_{3}^{-}-\mathrm{N}$ had a significant positive correlation with $\mathrm{NH}_{3}$ emission rates in Zone $\mathrm{C}$, but not in any other zone (see Table 3). This observation might be attributed to inhibition of nitrification by high $\mathrm{NO}_{3}^{-}-\mathrm{N}$ concentration. This inhibition would have caused the presence of $\mathrm{NH}_{4}^{+}-\mathrm{N}$ for a prolonged period leading to an increase in $\mathrm{NH}_{3}$ emission rates. Gunderson et al. (1998) and Carpenter-Boggs et al. (2000) discovered that $N$ fertilization including $\mathrm{NO}_{3}^{-}-\mathrm{N}$ decreased net $\mathrm{N}$ nitrification in soil significantly.

\subsection{Principal Components (PCs) Significantly Affecting Ammonia Volatilization}

Several methods are used to plot PCA results. For example, some researchers plot eigenvalues against principal components (Cattell, 1966; Raychaudhuri, 2000; Jolliffe, 2002). In this study, we chose to evaluate the variance proportion of each of the principal components because the eigenvalue ranges were dif- ferent for the five zones. Accordingly, the variance proportion was an appropriate criterion to compare among the five zones. Table 2 shows that the average $\mathrm{NH}_{3}$ emission rate in Zone $\mathrm{A}$ was 1459-fold greater than that in Zone $\mathrm{C}$. Indeed, $\mathrm{NH}_{3}$ emission rates differed substantially. In these various zones, the first four $\mathrm{PCs}$, i.e., soil type, $\mathrm{N}$ source, soil $\mathrm{pH}$, and soil temperature/moisture factors, contributed more than $80 \%$ of variance (see Fig. 2 ). Therefore, the four PCs across the five zones were considered as the most substantial factors governing $\mathrm{NH}_{3}$ emission from the fertilized soils in this study.

Examination of these histograms in Fig. 3 reveals that in each of the five zones clay, silt, sand, soil bulk density, field capacity, and electrical conductivity had large eigenvectors. The eigenvectors were essentially regression coefficients for the corresponding variables (Griffith, 2004). For example, the eigenvectors for the variable $F C$ in $P C 1$ were $0.40,0.37,0.37,0.37$ and 0.38 for Zones A, B1, B2, B3 and C, respectively. This result means that the regression coefficients between $\mathrm{FC}$ and $\mathrm{NH}_{3}$ emission rates were $0.40,0.37,0.37,0.37$ and 0.38 in $\mathrm{PCl}$ for the corresponding zones (see Fig. 3). These regression coefficients were always the largest or second largest values in $\mathrm{PC} 1$ for each of Zones A, B1, B2, B3 and C. The aforementioned six variables in each of the five zones are the signature of the soil type. Accordingly, soil type was the most important factor governing $\mathrm{NH}_{3}$ emission from fertilized soils.

Thus, PC1 symbolized the identity of the soil type in the five zones. In Zone A, clay, silt, sand, bulk density, FC, and EC had the same weight with absolute values of 0.40 , but sand and bulk density eigenvectors were negative. The sand content of the soils influences the bulk density as is evident from increases in bulk density of the soils with increasing sand content. For example, across the four soils evaluated in this study, the bulk density of Quincy Fine Sand ( $86.9 \%$ sand) was $1.43 \mathrm{~g} \mathrm{~cm}^{-3}$, while the bulk density of Biscayne Marl Soil ( $9.3 \%$ sand) was $0.88 \mathrm{~g} \mathrm{~cm}^{-3}$. Sand does not have many functional groups that can bind $\mathrm{NH}_{4}{ }^{+}$ions. Hence, a soil that contains greater sand content necessarily has lower potential to retain $\mathrm{NH}_{4}^{+}$ions. Thus, $\mathrm{NH}_{3}$ volatilization might be greater from sandy soils than from fine textured soils.

The variables including clay, silt, FC, and EC had positive regression coefficients in $\mathrm{PCl}$ across the five zones. Clay and silt particles have much greater specific surface areas and more functional groups than sand. Therefore, in this study the former fractions had much greater potential to retain $\mathrm{NH}_{4}^{+}$ions than the sand fraction. Consequently, $\mathrm{NH}_{3}$ emission rates tend to be lower in fine textured soils than in sand (Liu et al., 2007). The presence of clay and silt forms much smaller pores or capillaries than sand alone. This relationship is the basic reason why clay or silt soils have much greater FC than sandy soils (Minasny and McBratney, 2003).

Field capacity has positive regression coefficients with $\mathrm{PCl}$ (see Fig. 3). This statistical outcome might be explained by the fact that soils with greater FC generally contain greater proportions of clay and silt than soils with lower FC. Accordingly, soils with high water holding capacity might retain greater amounts of $\mathrm{NH}_{4}^{+}$and thereby decrease $\mathrm{NH}_{3}$ emission. Greater $\mathrm{EC}$ values were indicative of presence of greater amounts of metals and other ions occupying the functional groups of soil particles. Con- 


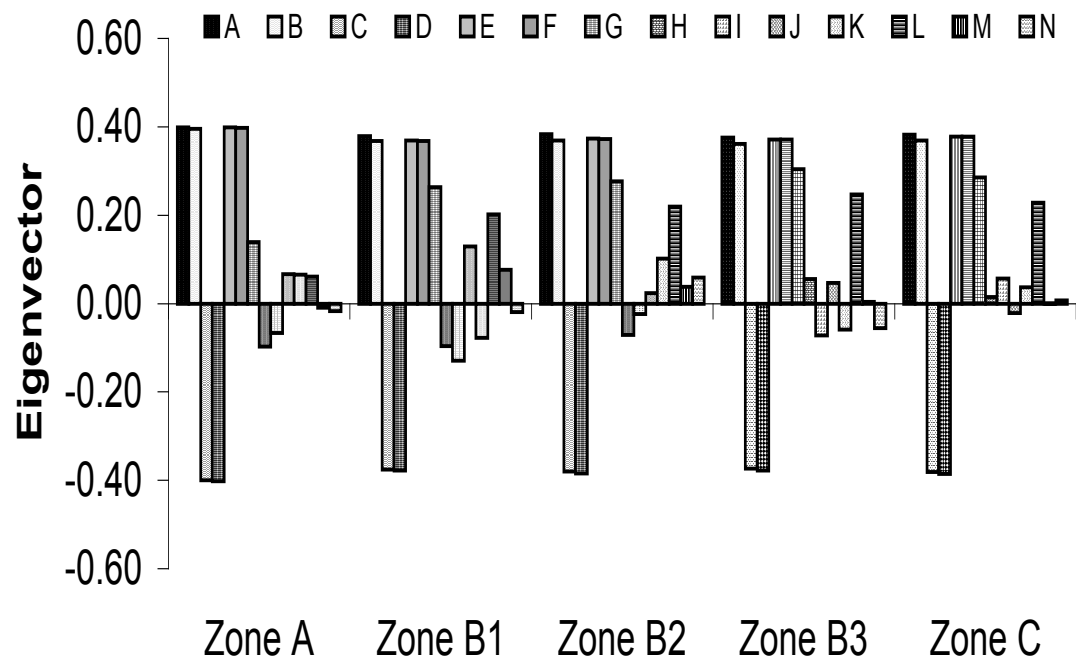

Fig. 3. Soil particle size distribution (i.e., clay, silt, and sand), bulk density, field capacity, and electrical conductivity, in the five zones, always had the 6 greatest absolute eigenvectors (i.e., characteristic vector) among the 14 variables. For the legend: $A=$ clay content; $B=$ silt content; $C=$ sand content; $D=$ bulk density; $E=$ electrical conductivity; $F=$ field capacity; $\mathrm{G}=$ organic matter; $\mathrm{H}=$ temperature; $\mathrm{I}=\mathrm{NH}_{4}{ }^{+}-\mathrm{N}$ rate; $\mathrm{J}=\mathrm{NO}_{3}^{-}-\mathrm{N}$ rate; $\mathrm{K}=$ incubation time; $\mathrm{L}=\mathrm{pH} ; \mathrm{M}=$ soil water regime; and $\mathrm{N}=\mathrm{NH}_{3}$ emission rate.

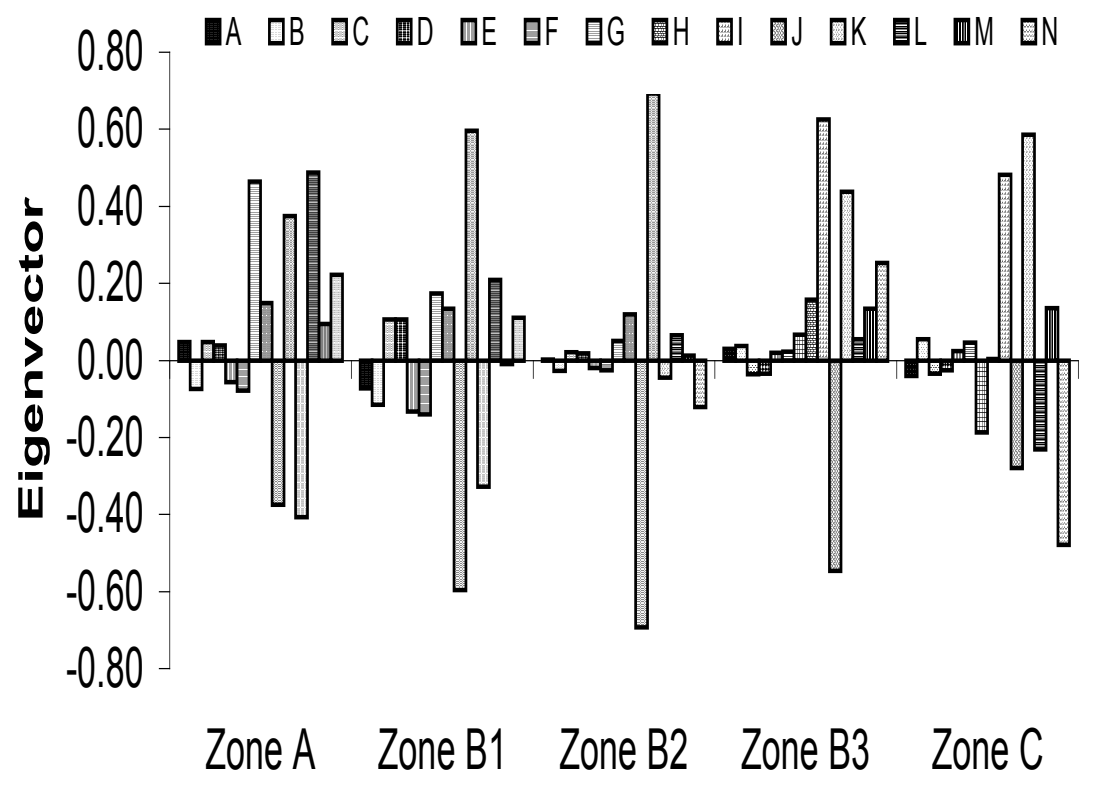

Fig. 4. Ammonium and nitrate, $P C 2$, in the five zones, possessed the main absolute eigenvectors. For the legend: $A=$ clay content; $B=$ silt content; $C=$ sand content; $D=$ bulk density; $\mathrm{E}=$ electrical conductivity; $\mathrm{F}=$ field capacity; $\mathrm{G}=$ organic matter; $\mathrm{H}=$ temperature; $\mathrm{I}=$ $\mathrm{NH}_{4}^{+}-\mathrm{N}$ rate; $\mathrm{J}=\mathrm{NO}_{3}^{-}-\mathrm{N}$ rate; $\mathrm{K}=$ incubation time; $\mathrm{L}=\mathrm{pH} ; \mathrm{M}=$ soil water regime; and $\mathrm{N}$ $=\mathrm{NH}_{3}$ emission rate. 


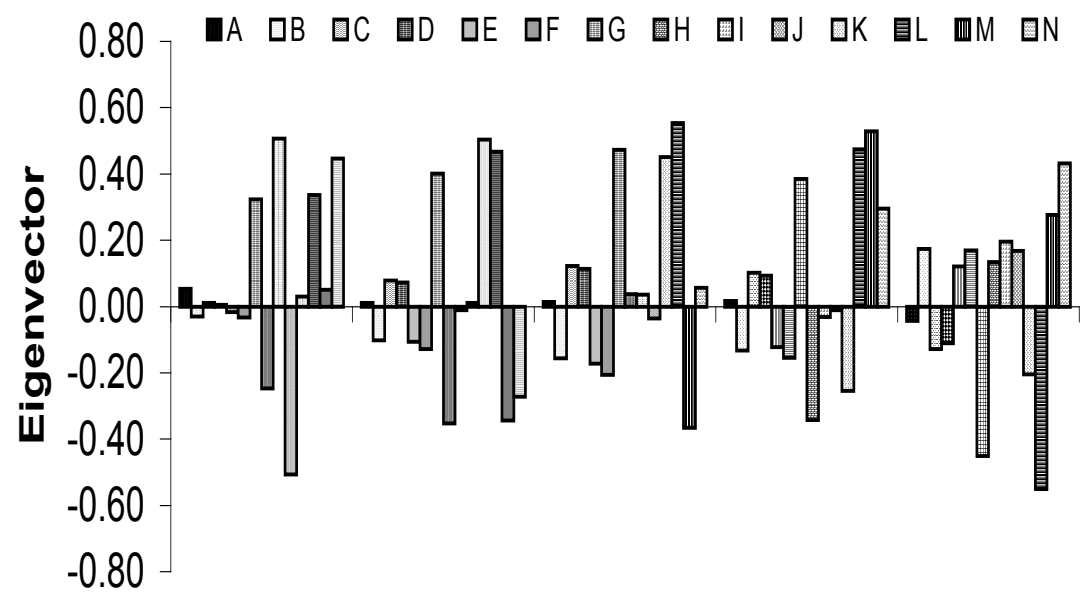

Zone A Zone B1 Zone B2 Zone B3 Zone C

Fig. 5. Soil $\mathrm{pH}, \mathrm{PC} 3$, in the five zones, was found to be the third factor. For the legend: $A=$ clay content; $B=$ silt content; $C=$ sand content; $D=$ bulk density; $E=$ electrical conductivity; $\mathrm{F}=$ field capacity; $\mathrm{G}=$ organic matter; $\mathrm{H}=$ temperature; $\mathrm{I}=\mathrm{NH}_{4}{ }^{+}-\mathrm{N}$ rate; $\mathrm{J}=\mathrm{NO}_{3}^{-}{ }^{-} \mathrm{N}$ rate; $\mathrm{K}=$ incubation time; $\mathrm{L}=\mathrm{pH} ; \mathrm{M}=$ soil water regime; and $\mathrm{N}=\mathrm{NH}_{3}$ emission rate.

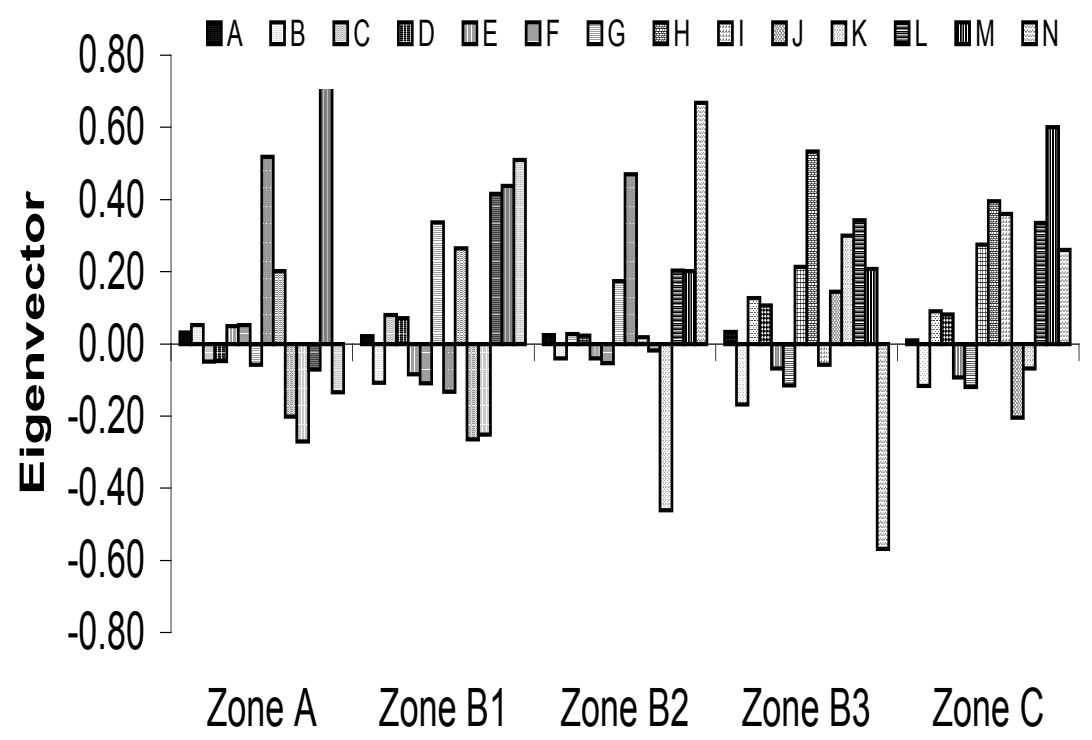

Fig. 6. The soil water regime and temperature, PC4, in the five zones, contributed to the preponderance of the variance of ammonia emission across the five zones. For the legend: $A=$ clay content; $B=$ silt content; $C=$ sand content; $D=$ bulk density; $E=$ electrical conductivity; $\mathrm{F}=$ field capacity; $\mathrm{G}=$ organic matter; $\mathrm{H}=$ temperature $; \mathrm{I}=\mathrm{NH}_{4}^{+}-\mathrm{N}$ rate; $\mathrm{J}=\mathrm{NO}_{3}^{-}-\mathrm{N}$ rate; $\mathrm{K}=$ incubation time; $\mathrm{L}=\mathrm{pH} ; \mathrm{M}=$ soil water regime; and $\mathrm{N}=\mathrm{NH}_{3}$ emission rate. 
sequently, there were few functional groups available for sorption of $\mathrm{NH}_{4}{ }^{+}$ions on the soil particles, thus, facilitating increased $\mathrm{NH}_{3}$ emission.

The eigenvectors for the soil water regime in $\mathrm{PCl}$ (soil type) were $-0.01,0.08,0.04,0.00$ and 0.00 for the five zones (see Fig. 3). These values were much lower than those for FC. This was quite expected since FC was reflective of soil properties and affected $\mathrm{NH}_{4}^{+}$adsorption. Accordingly, there was a greater positive correlation between $\mathrm{FC}$ and $\mathrm{NH}_{3}$ emission. However, the soil water regime impacted greatly on PC3 (Fig. 5) and on PC4 (Fig. 6) even though it impacted negligibly on PC2 (Fig. 4).

The contribution of soil $\mathrm{pH}$ to $\mathrm{PCl}$ was rather weaker than to PC2 (ammonium and nitrate) and to PC3 (soil pH) in Zone A, PC3 and PC4 (incubation temperature and soil moisture) in Zone B1, PC3 in Zone B2, Zone B3, and Zone C (see Figs. 3 though 6 ). These results showed that $\mathrm{pH}$ was not always the most important factor affecting $\mathrm{NH}_{3}$ emission rates; yet related publications categorize it as the most significant factor (He et al., 1999; Saffigna and Freney, 2002). This discrepancy might be attributed to the application of an advanced statistical tool in this study. This study demonstrated that soil particle size distribution characteristics had greater influence on $\mathrm{NH}_{3}$ emission than the soil $\mathrm{pH}$. Soil $\mathrm{pH}$ had little effect on $\mathrm{NH}_{3}$ emission for $\mathrm{PCl}$ in Zone $\mathrm{A}$ (see Fig. 3) because $62.7 \%$ of $\mathrm{NH}_{3}$ emission in Zone A occurred on Day 1 soon after $\mathrm{N}$ was applied to the soils. The high $\mathrm{NH}_{4}^{+}$concentration in the soil solution favored greater $\mathrm{NH}_{3}$ emission. Soil $\mathrm{pH}$ influenced $\mathrm{NH}_{3}$ emission during the later period of incubation because by then the $\mathrm{NH}_{4}^{+}$concentration in soil solution had declined and its effect on $\mathrm{NH}_{3}$ emission had diminished while the effect of $\mathrm{pH}$ had increased with time.

The influence of $\mathrm{NH}_{4}^{+}$and $\mathrm{NO}_{3}^{-}$(PC2) on $\mathrm{NH}_{3}$ emission, decreased in the order: Zones B1, B2, and B3 > Zone A $\approx$ Zone $C$ (Fig. 4). PC2 contributed from $12.9 \%$ to $17.9 \%$ to the total variances across the five zones. Accordingly, PC2 can be designated the "fertilizer" factor. The PC3 (soil pH) accounted for $9.6 \%$ to $15.5 \%$ of the total variances across the zones (see Fig. 5). The $\mathrm{pH}$ factor had regression coefficients of $0.34,0.47,0.55$, 0.47 , and -0.55 to the corresponding PC3 across all the zones, respectively. However, the contributions of the other variables differed with the zones. In Zone $\mathrm{A}, \mathrm{NH}_{3}$ emission rate, as well as concentrations of $\mathrm{NH}_{4}^{+}$and $\mathrm{NO}_{3}^{-}$had relatively high valves. Since the contribution of $\mathrm{NH}_{4}^{+}$and $\mathrm{NO}_{3}^{-}$were accounted for in PC2, these factors were not considered in PC3. In PC3, the contribution of $\mathrm{pH}$ was significant across all zones (see Fig. 5), therefore, PC3 can be called the "pH" factor (see Fig. 5). PC4, temperature and soil moisture, showed a significant effect on $\mathrm{NH}_{3}$ emissions across all zones. Hence, PC4 is considered as "temperature and soil moisture" factor (see Fig. 6).

The importance of soil $\mathrm{pH}$, moisture, temperature, source and rate of $\mathrm{N}$ in influencing $\mathrm{NH}_{3}$ emission has been reported by other investigations (Fenn and Hossner, 1985; He et al., 1999; Liu et al., 2007). The results of the current study demonstrated that soil particle size distribution, bulk density, FC, and EC also play a significant role in influencing $\mathrm{NH}_{3}$ emission. Therefore, soil type exerts an important role in influencing $\mathrm{NH}_{3}$ emission. However, this relationship was not recognized without the application of the sophisticated statistical analysis tool, PCA. Furthermore, some investigations on $\mathrm{NH}_{3}$ volatilization were conducted using only one soil type (Chantigny et al., 2004) which precluded the identification of the soil type as a major contributor to $\mathrm{NH}_{3}$ emission.

\section{Conclusions}

An advanced statistical analysis technique, PCA, was applied to a dataset with 600 data points from an incubation experiment involving four soils from Florida and Washington State amended with four $\mathrm{N}$ sources plus a control without fertilization, subjected to two soil water regimes and incubated at three different temperatures. The dataset was geometrically classified into five distinct zones of significant differences in $\mathrm{NH}_{3}$ volatilization rates. The geometrical classification indicated that $\mathrm{NH}_{4}^{+}$ concentration and soil water regime were important factors influencing $\mathrm{NH}_{3}$ emissions from soils to which $\mathrm{N}$ had been applied. The contribution of the $\mathrm{PCl}$ through PC4 accounted almost $90 \%$ of the total variance across the five zones. $\mathrm{PC} 1 \mathrm{~s}$ through $\mathrm{PC} 4 \mathrm{~s}$ were described as soil type, $\mathrm{N}$ source, soil $\mathrm{pH}$, and soil temperature/moisture factors, respectively. Ammonia emissions could be reduced substantially with amendment of coarse textured agricultural soils to reduce their bulk density, selection of fertilizers to decrease those with the ammonium compounds, use of amendments to lower soil $\mathrm{pH}$, and optimal soil moisture.

\section{Acknowledgements}

This research was supported by the Florida Agricultural Experiment Station and a grant from USDA-ARS. Professor Emeritus Waldemar Klassen at the University of Florida has given the authors constructive suggestions to improve this manuscript.

\section{References}

Aneja VA, WH Schlesinger, D Niyogi, G Jennings, W Gilliam, RE Knighton, CS Duke, J Blunden, and S Krishnan (2006) Emerging National Research Needs for Agricultural Air Quality. EOS 87(3): 25-36.

Balsera MA, W Wrioggers, Y Oomo, and K Schulten (1996) Principal component analysis and long time protein dynamics. J Phys Chem 100: 2567-2572.

Beauchemin S, D Hesterberg, and M Beauchemin (2002). Principal component analysis approach for modeling sulfur K-XANES spectra of humic acids. Soil Sci Soc Am J 66: 83-91.

Boussingault JB (1851) Die Landwirtschaft in ihren Beziehungen zur Chemie Physik und Meteorologie. Auflage II, Übersetzt von Graeger $\mathrm{H}$ Halle, Verlag von Ch Graeger.

Breeman N, N Van, PA Burrough, EJ Velthorst, HF Van Dobben, T De Wit, TB Ridder, and HFR Reijnders (1982) Soil acidification from atmospheric sulphate in forest canopy through-fall. Nature 299: 548-550.

Bremner JM and LA Douglas (1971) Decomposition of urea phosphate in soils. Soil Sci Soc Am Proc 35:575-578.

Buijsman E, HFM Maas, and WAH Asman (1987) Anthropogenic NH3 emissions in Europe. Atmos Environ 21: 1009-1022.

Bussink DWand O Oenema (1998) Ammonia volatilization from dairy farming systems in temperate areas: a review. Nutr Cycl Agroecosys 51: 19-33.

Carpenter-Boggs L, JL Jr Pikul, MF Vigil, and WE Riedell (2000) Soil 
nitrogen mineralization influenced by crop rotation and nitrogen fertilization. Soil Sci Soc Am J 64: 2038-2045.

Cattell RB (1966) The scree test for the number of factors. Multiv Behav Res 1: 245-276.

Chantigny MH, P Rochette, DA Angers, D Massé, and D Côté (2004) Ammonia volatilization and selected soil characteristics following application of anaerobically digested pig slurry. Soil Sci Soc Am J 68: 306-312.

EPA (1993) Ammonia Analysis Method: USEPA 350.1, Revision 2.0, Methods for the Determination of Inorganic Substances in Environmental Samples, EPA-600/R-93-100.

Fangmeier A, A Hadwiger-Fangmeier, L Eerden, and $\mathrm{H}$ van der Jäger (1994) Effects of atmospheric ammonia on vegetation: a review. Environ Pollut 86: 43-82.

FAO (2001) Global Estimates of Gaseous Emissions of NH3, NO and N2O from agricultural land. Food and Agriculture Organization of the United Nations (FAO) / International Fertilizer Industry Association (IFA), Rome, 106. Available online at http://www.fertilizer.org/ ifa.

Fenn LB and DE Kissel (1973) Ammonia volatilization from surface applications of ammonium compounds on calcareous soils. I. General Theory. Soil Sci Soc Am J 37: 855-859.

Fenn LB, RM Taylor, and JE Matocha (1981) Ammonia losses from surfaced-applied nitrogen fertilizer as controlled by soluble calcium and magnesium: General theory. Soil Sci Soc Am J 45: 777-781.

Fenn LB and LR Hossner (1985) Ammonia volatilization from ammonium or ammonium-forming nitrogen fertilizers. In: B.A. Stewart (eds.) Advances in Soil Science. Springer-Verlag New York, Inc. NY, USA, Vol 1, pp. 123-169.

Ferm M (1998) Atmospheric ammonia and ammonium transport in Europe and critical loads: a review. Nutr Cycl Agroecosys 51:5-17.

Fox RH and LD Hoffman (1981) The effect on $N$ fertilizer source on grain yield, $\mathrm{N}$ uptake, soil $\mathrm{pH}$, and lime requirement in no-till corn. Agron J 73: 891-895.

Gay SW and KF Knowlton (2005) Ammonia emission and animal agriculture. Virginia Cooperative Extension/Biological Systems Engineering. Publication 442-1 10, pp. 1-5.

Gnanadesikan R (1977) Methods for Statistical Data Analysis of Multivariate Observations. John Wiley \& Sons, Inc. New York, NY, USA.

Griffith DA (2004) Distributional properties of georefernced random variables based on the eigenfunction spatial filter. J Geograph Syst 6: 263-288.

Gunderson P, BA Emmet, OJ Kionaas, CJ Koopmans and A Tietema (1998) Impact of nitrogen deposition on nitrogen cycling in forests: A synthesis of NITREX data. For Ecol Manage 101: 37-56.

Hansen MN, SG Sommer, and N Madsen (2003) Reduction of Ammonia Emission by Shallow Slurry Injection: Injection Efficiency and Additional Energy Demand. J Environ Qual 32: 1099-1 104.

Hao Q, G Zhao and L Sun (2003) Factor analysis to the management performance of coal mine listed companies. Journal of Northwest Sci of TechUniversity of Agriculture and Forestry (Social Science Edition). 3: 106-109.

He ZL, AK Alva, DV Calvert, and DJ Banks (1999) Ammonia volatilization from different fertilizer sources and effects of temperature and soil pH. Soil Sci 164: 750-758.

Hirosawa Y, SE Marsh, and DH Kliman (1996) Application of standardized principal component analysis to land-cover characterization using multitemporal AVHRR data. Remote Sens Environ 58: 267-281.

Hotelling $H$ (1933) Analysis of a complex of statistical variables into principal components. J Educ Psychol 24: 417-441; 498-520.

Jolliffe IT (2002) Principal Component Analysis (2nd ed.). SpringerVerlag New York, Inc., NY, USA.

Kirchmann H, M Esala, J Morken, M Fem, W Bussink, J Gustavsson, C
Jakobsson (1998) Ammonia emissions from agriculture. Nutr Cycl Agroecosys 51: 1-3.

Liu GD, YC Li, and AK Alva (2007) High water regime can reduce ammonia volatilization from soils under potato production. Commun Soil Sci Plant Anal 38: 1-18.

Ma L, RW Malone, DB Jaynes, KR Thorp, and LR Ahuja (2008) Simulated effects of nitrogen management and soil microbes on soil nitrogen balance and crop production. Soil Sci Soc Am J 72: 1594-1603.

Malinowski ER (1991) Factor analysis in chemistry (2nd edition), John Wiley \& Sons, Inc., New York, NY, USA.

Minasny $B$ and $A B$ McBratney (2003) Integral energy as a measure of soil-water availability. Plant and Soil 249: 253-262.

Ouyang $Y(2005)$ Evaluation of river water quality monitoring stations by principal component analysis. Water Research 39: 2621-2635.

Ouyang Y, P Nkedi-Kizza, QT Wu, D Shinde, and CH Huang (2006) Evaluation of seasonal changes in river water quality. Water Res 40: 3800-3810.

Paulson KN and LK Kurtz (1969) Locus of urease activity in soil. Soil Sci Soc Am Proc 33: 897-901.

Pearson K (1901) On lines and planes of closest fit to systems of points in space. Philos Mag 6: 559-572.

Rao CR (1964) The use and interpretation of principal component analysis in applied research. Sankhya A 26: 329-358.

Raychaudhuri S, JM Stuart, and RB Altman (2000) Principal components analysis to summarize microarray experiments: application to sporulation time serious. Pacific Symposium on Biocomputing 5: 452-463.

Saffigna PG and JR Freney (2002) Volatilization of ammonia from agricultural soils. In: Rattan Lal (eds.) Encyclopedia of soil science, Marcel Dekker, New York, NY, USA, pp. 1380-1383.

Sanz-Cobena A, TH Misselbrook, A Arce, J Mingot, JA Diez, and A Vallejo (2008) An inhibitor of urease activity effectively reduces ammonia emissions from soil treated with urea under Mediterranean conditions. Agr Ecosyst Environ 126: 243-249.

SAS Institute (2007) SAS/STAT user's guide. Version 9.1.3. SAS Inst, Cary, NC, USA.

Shani U, A Ben-Gal, and LM Dudley (2005) Environmental implications of adopting a dominant factor approach to salinity management. J Environ Qual 34: 1455-1460.

Schlesinger WH and AE Hartley (1992) A global budget for atmospheric NH3. Biogeochemistry 15: 191-211.

Singh A, KD Casey, WD King, AJ Pescatore, RS Gates, and MJ Ford (2009) Efficacy of urease inhibitor to reduce ammonia emission from poultry houses. J Appl Poult Res 18: 34-42. doi:10.3382/ japr.2008-00046.

Sowers KE, WL Pan, BC Miller, and JL Smith (1994) Nitrogen use efficiency of split nitrogen applications in soft white winter wheat. Agron J 86: 942-948.

Sprengel C (1839) Die Lehre vom Dünger. Verlag J Müller, Leipzig

Vlek PLG and JM Stumpe (1978) Effect of solution chemistry and environmental conditions on volatilization losses from aqueous systems. Soil Sci Soc Am J 42: 416-421.

Watson CJ, H Miller, P Poland, DJ Kilpatrick, MDB Allen, MK Garrett, and $C B$ Christianson (1994) Soil properties and the ability of the urease inhibitor $\mathrm{N}$-(n-butyl) thiophosphoric triamide (nBTPT) to reduce ammonia volatilization from surface-applied urea. Soil Biol Biochem 26: 1165-1171.

Watson CJ, NA Akhonzada, JTG Hamilton, and DI Matthews (2008) Rate and mode of application of the urease inhibitor $\mathrm{N}$-(n-butyl) thiophosphoric triamide on ammonia volatilization from surfaceapplied urea. Soil Use Manage 24: 246-253.

Zhao M, G Li, and Z Zhang (2003) Study of characteristic organic compounds in red tide by factor analysis method. Marine Environ Sci 22: 1-6. 